\title{
Antioxidant Capacity, Cytoprotection, and Healing Actions of the Leaf Aqueous Extract of Ocimum suave in Rats Subjected to Chronic and Cold-Restraint Stress Ulcers
}

\author{
Paul V. Tan, ${ }^{1}$ C. Mezui, ${ }^{2}$ G. E. Enow-Orock, ${ }^{3}$ and G. Agbor ${ }^{4}$ \\ ${ }^{1}$ Department of Animal Biology and Physiology, Faculty of Science, University of Yaoundé I, P.O. Box 812, Yaoundé, Cameroon \\ ${ }^{2}$ Department of Animal Biology, Higher Teacher's Training College, University of Yaoundé I, Yaoundé, Cameroon \\ ${ }^{3}$ Department of Biomedical Sciences, Faculty of Health Sciences, University of Buea, Buea, Cameroon \\ ${ }^{4}$ Institute of Medical Research and Study of Medicinal Plants (IMPM), Yaoundé, Cameroon \\ Correspondence should be addressed to Paul V. Tan; pvernyuy@yahoo.com
}

Received 24 November 2012; Accepted 1 March 2013

Academic Editor: Gyula Mozsik

Copyright (C) 2013 Paul V. Tan et al. This is an open access article distributed under the Creative Commons Attribution License, which permits unrestricted use, distribution, and reproduction in any medium, provided the original work is properly cited.

\begin{abstract}
We evaluated the qualitative chemical composition and tested the antiulcer actions on cold/restraint stress ulcers, the healing effect on chronic acetic acid-induced gastric ulcers, and the in vivo and in vitro antioxidant capacity of Ocimum suave extract. Triterpenes, flavonoids, sugars, phenols, sterols, and multiple bonds were among the phytochemicals detected. The extract $(250-500 \mathrm{mg} / \mathrm{kg})$ dose-dependently inhibited the formation of gastric ulcers induced by cold/restraint stress (52.30\%-83.10\%). The prophylactic actions were associated with significant increases in gastric mucus production. There was significant histological healing of chronic ulcers following 14-day treatment with $O$. suave extract $(250-500 \mathrm{mg} / \mathrm{kg})$. We also evaluated the efficacy of $O$. suave extract in cold/restraint-induced oxidative stress in rat stomach tissue. O. suave $(500 \mathrm{mg} / \mathrm{kg})$ ameliorated the decreased levels of reduced glutathione from 0.85 (control group) to $2.08 \mathrm{nmol} / \mathrm{g}$ tissue. The levels of SOD and catalase were also improved in rats treated with O. suave extract. The extract had a high phenol content ( $899.87 \mathrm{mg}$ phenol/g catechin equivalent), in vitro DPPH radical scavenging activity $(89.29 \%)$, and FRAP (antioxidant capacity) $(212.64 \mathrm{mg} / \mathrm{g}$ catechin equivalent). The cytoprotective and ulcer healing effects of the extract are attributed to enhanced mucus production and the antioxidant properties which may likely be associated with the high presence of flavonoids and polyphenols.
\end{abstract}

\section{Introduction}

The stressful nature of modern life makes the gastroduodenal viscus susceptible to physical and nervous stress. In the latter situation, vagal stimulation can cause hypersecretion of acid and pepsin resulting in gastroduodenal ulceration enhanced by the release of stress hormones of the steroid type [1]. Experimentally-induced ulcers of the cold/restraint type in laboratory animals are regularly used to mimic the real life stress situation in humans and permit the evaluation of the stress ulcer inhibiting effects of drugs and plant-derived antiulcer preparations. Lipid peroxidation has been linked to the mechanism of cold stress ulcer induction. In rats, water immersion/restraint stress stimulates lipid peroxidation and sulphydryl oxidation via oxygen free radicals generated by the xanthine-xanthine oxidase system, and infiltrated neutrophils in gastric mucosal tissue are involved in the progression of acute gastric mucosal lesions [2]. Oxygenderived free radicals are cytotoxic and promote tissue injury, while radical scavengers stimulate the healing of refractory peptic ulcers [3]. Thus, the antioxidant capacity of drugs and medicinal plant preparations can be used to explain their antiulcer mechanisms of action.

Ocimum suave Willd (Lamiaceae, syn.: Labiatae [4], syn.: Menthaceae [5]) is a seasonal aromatic shrub which grows specifically at high altitudes, and is used in ethnomedicine to treat ulcers, fever, stomach ache, and bronchopneumonic infections [6-8]. The oil from $O$. suave leaves contains phenols, and from preliminary phytochemical work, we have noted the predominance of triterpenes in the leaf extract. The extract also has acaricidal [9] mosquito repellent [10,11], analgesic [12], antipyretic [13], and antimicrobial properties [14]. 
The leaf methanol extract of $O$. suave has cytoprotective effects against $\mathrm{HCl} /$ ethanol, absolute ethanol, indomethacin, and pylorus ligation ulcer models [15]. These models are used for the rapid screening of potential antiulcer products, but much of the judgement of their cytoprotective and antisecretory potential is limited to the macroscopic absence or reduction of gastric mucosal lesions and provides no information on the actual microscopic situation [16]. On the contrary, while stress ulcer models closely reflect the realities of the stressful human situation, chronic acetic ulcers often penetrate into the underlying gastric muscle layers and offer the opportunity to monitor the healing effects of new products on well-established gastric ulcer craters. The present experiment was therefore designed to study the ability of the leaf aqueous extract of $O$. suave to prevent the formation of cold stress/restraint-induced gastric lesions, as well as its healing effects on chronic acetic acid-induced gastric ulcers. In addition, in vivo and in vitro antioxidant tests were used to explore the possible mode of antistress action of the extract.

\section{Materials and Methods}

2.1. Animals. The male Wistar rats (160-200 g) used were raised on a standard laboratory diet and tap water in the animal house of the Faculty of Science, University of Yaounde 1. Prior authorization for the use of laboratory animals in this study was obtained from the Cameroon National Ethics Committee (Reg. No. FWA-IRB00001954). The use, handling and care of animals were done in adherence to the European Convention (Strasbourg, 18.III.1986) for the protection of vertebrate animals used for experimental and other purposes (ETS-123), with particular attention to Part III, articles 7, 8, and 9.

\subsection{Extract Preparation and Quantitative Phytochemical Tests.} The plant material was collected in Jakiri in the North West Region of Cameroon. Botanical identification was done at the National Herbarium in Yaoundé by comparison with existing herbarium specimen $\mathrm{N}^{\circ}$ HNC: 6077/6914 (R. Letouzey). The fresh leaves were sun dried and ground into a fine powder. The dried ground leaves were extracted in water by boiling $1 \mathrm{~kg}$ in 1 litre of water for 15 minutes. The extract solution was filtered through four layers of cheesecloth and then through Whatman filter paper No. 3. The resulting solution was evaporated at $50^{\circ} \mathrm{C}$ using a convection air oven (Jencons-PLS, UK) to obtain $20 \mathrm{~g}$ of a brown solid. The extract redissolved readily in distilled water which was used as the vehicle.

The extract was subjected to the Liebermann Burchard, Schinoda, Meyer, and Molisch tests (for triterpenes, flavonoids, alkaloids, and sugars, resp.), as well as characterisation tests for the presence of phenols, sterols, and multiple bonds [17].

2.3. Cold Stress-Induced Gastric Lesions. Stress-induced gastric ulcers were provoked in rats using the method of Takagi and Okabe (1968) described by others [18]. Following $12 \mathrm{~h}$ of food (but not water) deprivation, test rats were given the extract $(250$ and $500 \mathrm{mg} / \mathrm{kg}$ ) by oral route while control rats received the vehicle. One hour later, the rats were placed in small individual wire cages and immersed in cold water at $21-23^{\circ} \mathrm{C}$ up to the level of the xiphoid. 90 minutes later, the rats were removed and sacrificed under ether anaesthesia. The stomachs were removed and the gastric lesions produced were measured and the lesion indices expressed as the sum of the lengths of the lesions for each rat.

2.4. Acetic Acid-Induced Chronic Ulcers. The glacial acetic acid chronic ulcer model was used [19]. Briefly, laparotomy was performed under ether anaesthesia on experimental rats after a $12 \mathrm{~h}$ fast. Fifty microlitres of $30 \%$ glacial acetic acid were injected into the wall of the stomach corpus at the region of the lesser curvature and the stomach wall wiped using cotton wool soaked in a $0.9 \% \mathrm{NaCl}$ solution. The abdominal incisions were stitched up and feeding was resumed. Disinfectant (Betadine) was applied daily to avoid infection. Four days after the operation, a control group of six rats (group1) was killed using ether, and their stomachs were opened in order to establish the degree of ulceration prior to the onset of treatment. The remaining rats were divided into five groups of six rats each: group 1 (ulcerated controls) received $1 \mathrm{~mL}$ of distilled water daily by gavage for two weeks, while groups 2,3 , and 4 were given, respectively, 125 , 250 , and $500 \mathrm{mg} / \mathrm{kg}$ of the extract in $1 \mathrm{~mL}$ of distilled water. Group 5 rats were given $50 \mathrm{mg} / \mathrm{kg}$ of ranitidine (Azantac). An additional group of 6 healthy nonulcerated rats was included but the rats were given neither the extract nor ranitidine. Food and water intakes were measured daily and on the final day the rats were sacrificed and ulcer indices and gastric mucus production were measured. Ulcer healing rates were calculated by comparing the ulcer status of extract- and ranitidine-treated rats with those of the ulcerated untreated controls. The degree of autohealing was evaluated by comparing the untreated controls with the rats killed on day 4 operation. The stomachs were weighed, fixed and stored in formaldehyde awaiting histological studies.

2.5. Measurement of Mucus Production. The mucus covering of each stomach was gently scraped using a glass slide and the mucus weighed carefully using a sensitive digital electronic balance. The same experimenter performed this exercise each time.

\subsection{Measurement of In Vitro Antioxidant Capacity of Ocimum suave Extract}

2.6.1. Measurement of Folin Antioxidant Capacity. FolinCiocalteu reagent (Sigma Chemical Co., St. Louis, MO) was diluted 10-fold and used for the measurement of the Folin antioxidant capacity of the extract [20], and absorbance was measured at $750 \mathrm{~nm}$ after $10 \mathrm{~min}$. of reaction, using catechin as the standard.

2.6.2. Measurement of Ferric Reducing Antioxidant Power (FRAP). The ferric reducing antioxidant ability of the extract was measured by spectrophotometry [21]. The FRAP reagent $(2 \mathrm{~mL})$ was mixed with $30 \mu \mathrm{L}$ of hydrolysed extract and the absorbance was read at $593 \mathrm{~nm}$ after 12 minutes of incubation using a Spectronic GENESYS 5 incubator (Milton Roy Co.) equipped with a thermostat, autocell heating, and 
TABLE 1: Effect of the leaf aqueous extract of $O$. suave on gastric lesions induced by cold stress in rats.

\begin{tabular}{lcccccc}
\hline Treatment & Dose $(\mathrm{mg} / \mathrm{kg})$ & $N$ & \% Ulcerated surface & Ulcer index (mean \pm SEM) & Inhibition (\%) & Mucus production (mg) \\
\hline Control & - & 6 & 0.77 & $6.50 \pm 1.18$ & - & $40.11 \pm 0.66$ \\
Extract & 250 & 6 & 0.29 & $3.10 \pm 1.31^{*}$ & 52.3 & $61.52 \pm 9.75^{*}$ \\
Extract & 500 & 6 & 0.06 & $1.10 \pm 0.45^{* *}$ & 83.1 & $75.71 \pm 4.48^{* *}$ \\
Sucralfate & 200 & 6 & 0.30 & $3.52 \pm 0.21^{*}$ & 45.8 & $75.76 \pm 6.08^{* *}$ \\
\hline
\end{tabular}

Statistically different relative to control; ${ }^{*} P<0.05 ;{ }^{* *} P<0.05$

$N$ : number of rats.

The values are expressed as mean \pm SEM.

cooling water bath (Fischer Scientific). The temperature was maintained at $37^{\circ} \mathrm{C}$ and catechin was used as standard.

\subsubsection{Measurement of DPPH Scavenging Activity. DPPH (1,1-} diphenyl-2-picrylhydrazyl) radical scavenging activity of the extract was measured as earlier described [22]. An aliquot of the extract in methanol $(10 \mathrm{mg} / \mathrm{mL})$ was added to methanolic solutions of DPPH $(1 \mathrm{mM}, 0.25 \mathrm{~mL})$. The mixture was shaken and left to stand for 30 minutes at room temperature. The absorbance of the solution was measured spectrophotometrically at $517 \mathrm{~nm}$ and the \% DPPH scavenging activity was calculated against the control.

2.7. Measurement of In Vivo Antioxidant Capacity of Ocimum suave Extract. Cold/restraint stress-induced gastric ulcers were provoked in rats given previously $1 \mathrm{~mL}$ distilled water (controls) 250 or $500 \mathrm{mg} / \mathrm{kg}$ of extract (test groups) as described here previously [18]. Blood and gastric tissue samples were taken and prepared for the measurement of different oxidative stress parameters: lipid peroxidation was assessed by measuring the levels of malondialdehyde (MDA) in gastric tissue samples [23]. Quantification of MDA was done using an extinction coefficient of $1.56 \times 10^{6} \mathrm{M}^{1} / \mathrm{cm}^{-1}$ and expressed as pmol of MDA per $\mathrm{g}$ of wet stomach tissue. Cellular glutathione was measured based on the reaction between 2,2-dithio-5, $5^{\prime}$-dibenzoic acid and the thiol (SH) groups of glutathione to yield a complex whose absorbance was read at $412 \mathrm{~nm}$ [24]. The glutathione concentration was calculated using the molar extinction coefficient $\varepsilon=$ $13600 \mathrm{~cm} / \mathrm{mol}$ and the results expressed in $\mathrm{nmol} / \mathrm{g}$ of tissue. Superoxide dismutase (SOD) activity was measured using a standard method [25] and tissue protein was measured using the Biuret method of protein assay. Catalase (CAT) was determined [26] and expressed as $\mu \mathrm{mol}$ of $\mathrm{H}_{2} \mathrm{O}_{2}$ per min per $\mathrm{mg}$ of protein.

2.8. Statistical Analysis. Values in tables are given as arithmetic means \pm standard error of the mean (S.E.M.) The significance of differences between means was calculated using the Student's $t$-test.

\section{Results}

3.1. Antiulcer Actions. The effects of subjecting the rats to a combination of restraint and cold stress are shown in Table 1. Control rats developed haemorrhagic lesions in the glandular portions of their stomachs 6 hours after cold immersion.
O. suave extract $(250-500 \mathrm{mg} / \mathrm{kg})$ dose-dependently prevented the formation of gastric lesions, inhibition attaining $83 \%$ at the dose of $500 \mathrm{mg} / \mathrm{kg}$. Sucralfate $(200 \mathrm{mg} / \mathrm{kg})$ prevented lesion formation by $46 \%$. Mucus production increased from $40 \mathrm{mg}$ in the controls to $76 \mathrm{mg}$ for sucralfate and the highest dose of extract.

3.2. Antioxidant Activity. The ferric reducing antioxidant power (FRAP) of the aqueous extract of $O$. suave was $212.64 \pm$ $12.24 \mathrm{mg} / \mathrm{g}$ catechin equivalent. Antioxidant capacity, measured as a function of the extract phenol content, was $899.87 \pm$ $32.61 \mathrm{mg} / \mathrm{g}$ catechin equivalent, while the percentage DPPH radical scavenging activity was 89.29 . Table 2 shows the in vivo antioxidant capacity of the aqueous extract of $O$. suave. Reduced glutathione, catalase, and superoxide dismutase (SOD) were decreased in the control groups. The O. suave extract $(250-500 \mathrm{mg} / \mathrm{kg})$ ameliorated the decreased levels of SOD and reduced glutathione from $58.10 \pm 5.24$ to $66.80 \pm$ 1.70 units/g tissues and from $0.85 \pm 0.12$ to $2.08 \pm 0.53 \mathrm{nmol} / \mathrm{g}$ tissues, respectively. The level of catalase was also improved in rats treated with the $O$. suave extract $(250 \mathrm{mg} / \mathrm{kg})$ and the level of MDA was decreased in rats treated with $O$. suave $(250 \mathrm{mg} / \mathrm{kg})$. In contrast, in rats treated with the highest dose of extract the levels of MDA were increased despite the fact that the ulcer index was reduced.

3.3. Ulcer Healing. Table 3 shows a dose-dependent enhancement of the healing of acetic acid-induced chronic gastric ulcers (84 to $93 \%$ ) following daily treatment with increasing doses of extract. A healing rate of $58 \%$ was recorded for Ranitidine $(50 \mathrm{mg} / \mathrm{kg})$. Unlike ranitidine, O. suave extract promoted significantly higher levels of mucus production (73-76 mg at $250-500 \mathrm{mg} / \mathrm{kg}$ ) during the treatment period compared with the controls $(54 \mathrm{mg} / \mathrm{kg})$. However, O. suave as well as ranitidine-treated rats showed a slight reduction in the total protein content of the mucus obtained at the end of the treatment period $(0.287 \pm 0.034$ and $0.242 \pm$ $0.061 \mathrm{mg} / \mathrm{mg}$, resp.) compared with the controls $(0.345 \pm$ $0.023 \mathrm{mg} / \mathrm{mg}$ ). Table 4 shows the change in body weight of the animals during the treatment of acetic ulcers. There was no clear tendency for weight gain (as a side effect) during short-term intake of the extract. Figure 1 shows the macromorphological presentation of gastric mucosa of the rats after acetic acid ulcer induction. Figure 1(b) (control $\left.{ }^{2}\right)$ shows that 4 days after ulcer induction the gastric mucosa presents with well-defined gastric ulcer craters measuring $81 \mathrm{~mm}^{2}$ on average. Two weeks after ulcer induction, rats that received the vehicle (Figure 1(c)) still had ulcer craters but 
TABLE 2: In vivo antioxidant capacity of $O$. suave extract in rats subjected to cold restraint stress.

\begin{tabular}{lcccc}
\hline & & \multicolumn{2}{c}{ Dose } \\
& Normal rats & $0 \mathrm{mg} / \mathrm{kg}$ & $250 \mathrm{mg} / \mathrm{kg}$ & $500 \mathrm{mg} / \mathrm{kg}$ \\
\hline Specific activity of SOD (units/g tissue) & $62.92 \pm 2.20$ & $58.10 \pm 5.24$ & $60.72 \pm 1.48$ & $66.80 \pm 1.70$ \\
Specific activity of CAT $\left(\mu \mathrm{M} \mathrm{H} \mathrm{H}_{2} / \mathrm{min} . / \mathrm{g}\right.$ tissue) & $179.50 \pm 9.97$ & $90.87 \pm 8.43^{*}$ & $105.32 \pm 12.11^{*}$ & $105.00 \pm 0.06^{*}$ \\
Malondialdehyde (pmol/g wet tissue) & $3.70 \pm 0.53$ & $9.42 \pm 0.26$ & $8.70 \pm 0.32$ & $9.72 \pm 0.06$ \\
Reduced glutathione (nmol/g tissue) & $1.61 \pm 0.05$ & $0.85 \pm 0.12$ & $1.10 \pm 0.21$ & $2.08 \pm 0.53^{*}$ \\
\hline
\end{tabular}

Statistically different relative to normal rats, ${ }^{*} P<0.05$.

The values are expressed as mean \pm SEM of 6 animals.

SOD: superoxide dismutase; CAT: catalase.

TABLE 3: Healing effect of the leaf aqueous extract of $O$. suave on chronic acetic acid-induced gastric ulcers in rats.

\begin{tabular}{lcccccc}
\hline Treatment & Extracted dose $(\mathrm{mg} / \mathrm{kg})$ & $N$ & Ulcerated area $\left(\mathrm{mm}^{2}\right)$ & \% Healing & Mucus production $(\mathrm{mg})$ & Stomach relative weight $(\%)$ \\
\hline Healthy control & - & 6 & 0 & - & $60.53 \pm 3.83$ & $1.05 \pm 0.04$ \\
Group 1 & - & 6 & $81.00 \pm 13.37$ & - & $55.26 \pm 3.38$ & $1.79 \pm 0.16^{\Psi}$ \\
Group 2 & - & 6 & $47.00 \pm 2.49$ & 41.9 & $54.25 \pm 4.14$ & $1.25 \pm 0.13$ \\
Group 3 & 125 & 6 & $7.30 \pm 3.35$ & $84.5^{* *}$ & $52.39 \pm 2.24$ & $1.05 \pm 0.07$ \\
Group 4 & 250 & 6 & $4.05 \pm 1.64$ & $91.4^{* *}$ & $72.60 \pm 7.99^{*}$ & $0.97 \pm 0.07$ \\
Group 5 & 500 & 6 & $3.20 \pm 1.53$ & $93.2^{* *}$ & $75.71 \pm 7.24^{*}$ & $1.09 \pm 0.12$ \\
Group 6 (ranitidine) & 50 & 6 & $9.20 \pm 2.15$ & $80.4^{* *}$ & $58.13 \pm 4.39$ & $1.22 \pm 0.15$ \\
\hline
\end{tabular}

$N$ : number of rats.

Statistically different relative to group $2,{ }^{*} P<0.05,{ }^{* *} P<0.01$.

Statistically different relative to group $1,{ }^{\Psi} P<0.01$.

Healthy control: healthy, nonulcerated control rats.

Group 1 (ulcerated rats sacrificed 4 days after acetic acid ulcer induction), showing a deep large ulcer (about $81 \mathrm{~mm}^{2}$ ), with raised edges and sclerous interior. Group 2 (ulcerated rats given vehicle for 14 days following ulcer induction).

Groups 3, 4, and 5 ulcerated rats treated with 125, 250, and $500 \mathrm{mg} / \mathrm{kg}$ bw of extract, respectively, for $14 \mathrm{~d}$ after day 4 of ulcer establishment.

Positive control rat given ranitidine $(50 \mathrm{mg} / \mathrm{kg}$ bw) for $14 \mathrm{~d}$ after ulcer establishment.

with some degree of autohealing. Treatment with O. suave extract or ranitidine was associated with increased mucus production and significant reduction of ulceration (Figures $1(\mathrm{~d})-1(\mathrm{~g}))$ compared with the 4-day controls.

Figure 2 presents the results obtained from histological studies. Figure 2(a) shows the stomach section for a normal rat that was not subjected to acetic acid ulceration. The gastric mucosal glands (GMs) are normal, and annular muscles (AMs) and longitudinal muscles (LMs) in the muscularis are intact. Histological examination of the control group 4 days after ulceration (as well as the vehicle-treated controls) showed that the deep ulcer craters had superficial loss of substance, with the denuded mucosa covered by serofibrinous exudates. Many inflammatory cells could be seen in the interstitial tissue. Fibrosis, sclerosis, and oedema were also observed (Figures 2(b)-2(f)). The histological presentation was characteristic of a chronic ulcerative gastritis. In the rats treated with Ocimum suave $(125 \mathrm{mg} / \mathrm{kg})$, ulcer healing was shown by the size of the glands around the area of healing, disappearance of fibrosis but with some persistent oedema, and sclerosis (Figures 2(g)-2(h)). 14 days following treatment with the extract ( 250 and $500 \mathrm{mg} / \mathrm{kg}$ ), the ulcer craters viewed at the macromorphological level had vanished and the scars were covered by a layer of mucus. There was disappearance of fibrosis, sclerosis, and lymphocyte infiltrations, with normal mucosa without glandular destruction (Figure 2(i)). The mucosa of ulcerated rats treated with ranitidine showed advanced scar tissue formation but there was persistent oedema in the muscularis mucosa (Figure 2(j)).

\section{Discussion}

The experimental model of acute gastritis such as water immersion/restraint stress-induced gastric injury is a useful tool in the examination of the pathomechanism of acute gastritis. In acute stress ulcer, intraluminal acid must be present for mucosal damage to occur [27] and gastric adherent mucus plays a vital role in protecting the mucosa against ulceration. The stress ulcer model increases gastric acid secretion [28], reduces gastric adherent mucus, and decreases the concentration of sialic acid [29], and antiulcer products that enhance adherent gastric mucus production are therefore useful in preventing acute stress ulcer. Thus the protective role of mucus as a possible mode of action was evident as the results show that $O$. suave extract $(500 \mathrm{mg} / \mathrm{kg})$ and sucralfate significantly increased mucus production compared with the controls. In previous work [30], we have observed that although the extract has no antisecretory or acid neutralising effects, it is capable of inhibiting pylorus ligation-induced gastric lesions in highly acidic gastric environments (up to $91 \mathrm{mEq} / \mathrm{l}$ ) without reducing the pepsin activity of the gastric juice. In addition, the total protein content of gastric mucus was not influenced by the extract, suggesting that the mechanism of action does not involve an enhancement of the physicochemical aspect of the mucus. 
TABLE 4: Effect of O. suave leaf extract on the body weight change $(\mathrm{g})$ of rats during the healing period.

\begin{tabular}{|c|c|c|c|c|c|}
\hline & \multirow{2}{*}{ Control } & \multicolumn{3}{|c|}{ Ocimum suave } & \multirow{2}{*}{$\begin{array}{l}\text { Ranitidine } \\
(50 \mathrm{mg} / \mathrm{kg})\end{array}$} \\
\hline & & $(125 \mathrm{mg} / \mathrm{kg})$ & $(250$ mg/kg) & $(500 \mathrm{mg} / \mathrm{kg})$ & \\
\hline Initial weight & $155.3 \pm 7.6$ & $170.7 \pm 5.2$ & $174.9 \pm 5.9$ & $160.2 \pm 6.7$ & $168.0 \pm 10.9$ \\
\hline Final weight & $170.1 \pm 6.8$ & $187.4 \pm 6.2$ & $198.1 \pm 3.9$ & $179.1 \pm 8.1$ & $186.6 \pm 14.5$ \\
\hline$\%$ weight gain & 10.8 & 9.8 & 13.2 & 11.8 & 11.1 \\
\hline
\end{tabular}

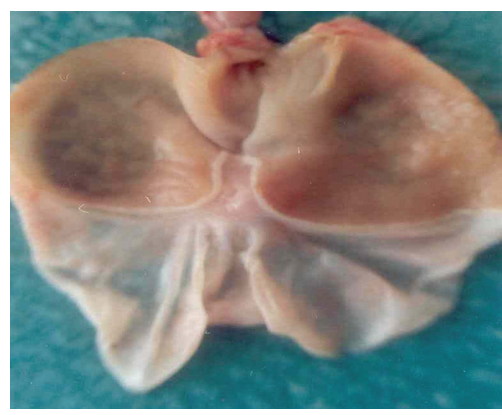

(a)

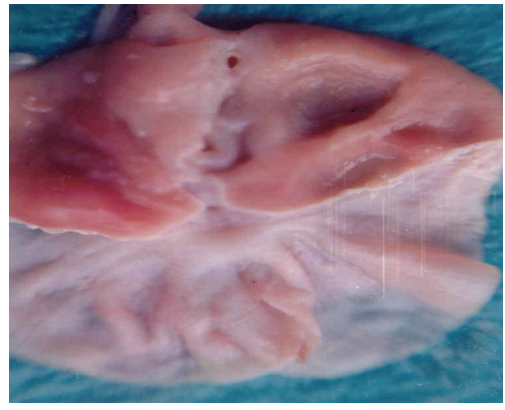

(d)

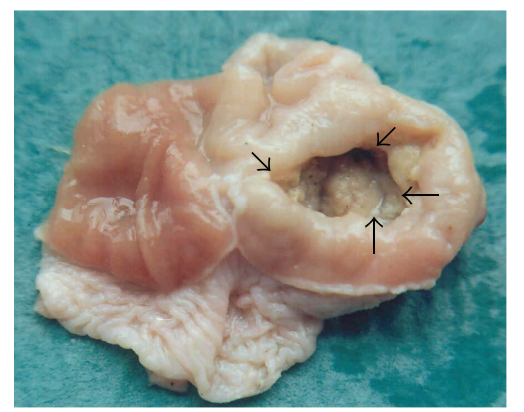

(b)

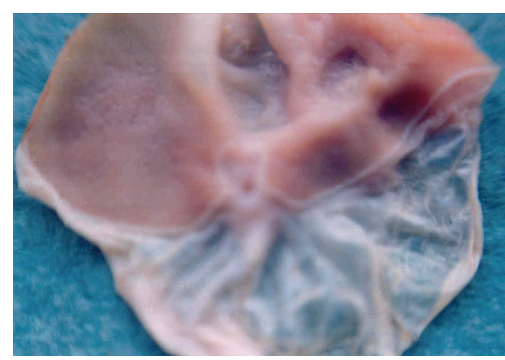

(e)

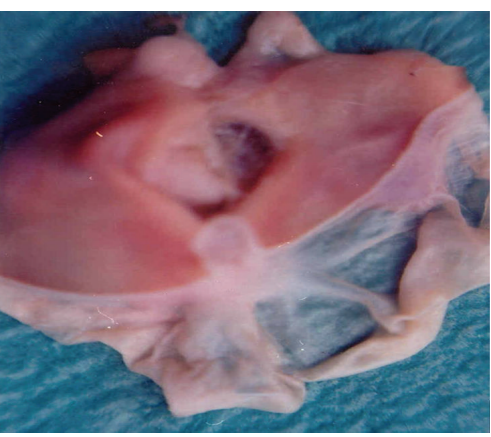

(g)

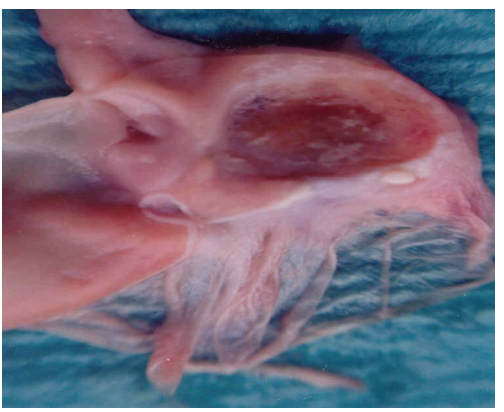

(c)

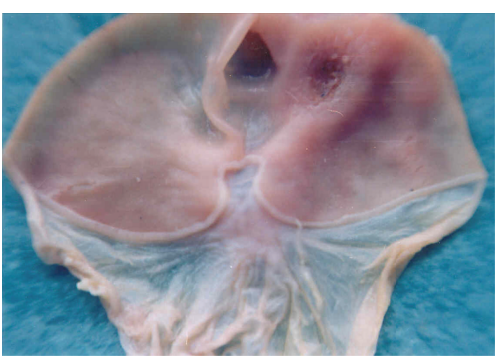

(f)

FIGURE 1: Macromorphological presentation of chronic acetic acid-induced gastric ulcers (ulcers are located on the right half of each photo, (b)-(g)). (a) Healthy control rat. (b) Group 1 (ulcerated rats sacrificed 4 days after acetic acid ulcer induction), showing a deep large ulcer (about $81 \mathrm{~mm}^{2}$ ), with raised edges and sclerous interior. (c) Group 2 (ulcerated rats given vehicle for 14 days following ulcer induction). (d)-(f) Groups 3, 4, and 5 ulcerated rats treated with 125, 250, and $500 \mathrm{mg} / \mathrm{kg}$ bw of extract, respectively, for $14 \mathrm{~d}$ after day 4 of ulcer establishment. (g) Positive control rat given ranitidine $(50 \mathrm{mg} / \mathrm{kg} \mathrm{bw})$ for $14 \mathrm{~d}$ following ulcer establishment.

In addition to the increased gastric secretion, the stress ulcer model stimulates oxygen-derived radical production [31]. The resulting oxygen-derived free radicals can, among other mechanisms, provoke tissue damage by inducing ischemia, and radical scavengers like superoxide dismutase are effective in reducing the adverse effects of free radicals on gastric mucosa $[32,33]$. Other radical scavenging substances like DMSO, allopurinol, DL-cysteine, retinol, tocopherol, malonic dialdehyde offer protection against stress-induced ulceration even in hyperacidic gastroduodenal environments $[34,35]$. The free radicals are formed in endothelial cells and polymorphonuclear neutrophils (PMNs), causing vascular endothelial cell damage which is evidenced by the release of endothelial cell SOD into the plasma [36]. The role of 


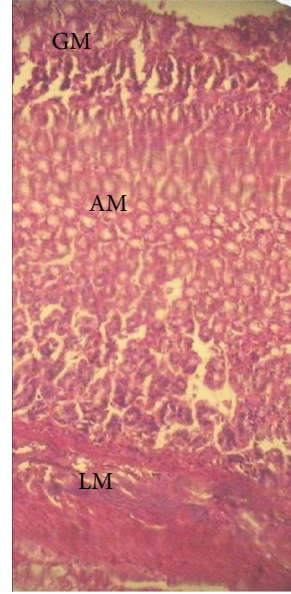

(a)

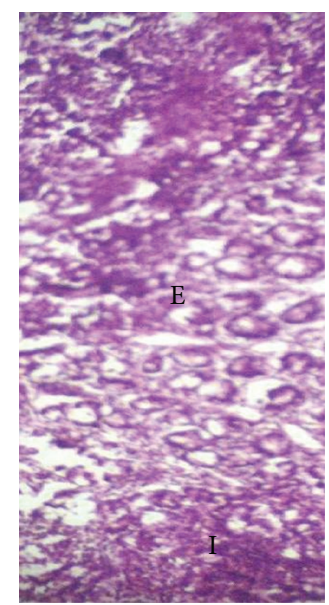

(f)

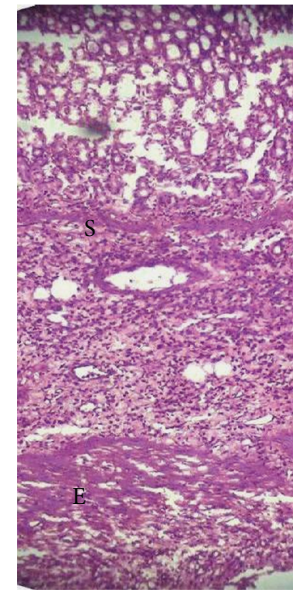

(b)

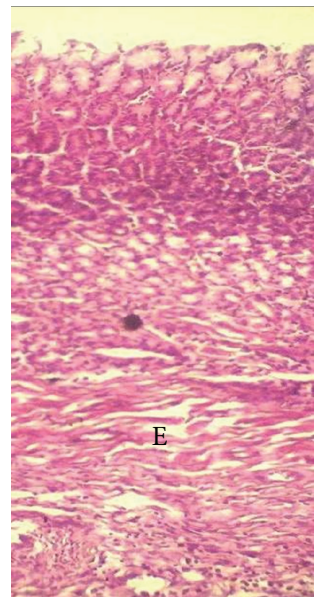

(g)

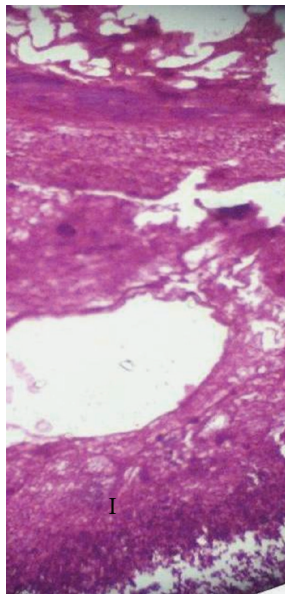

(c)

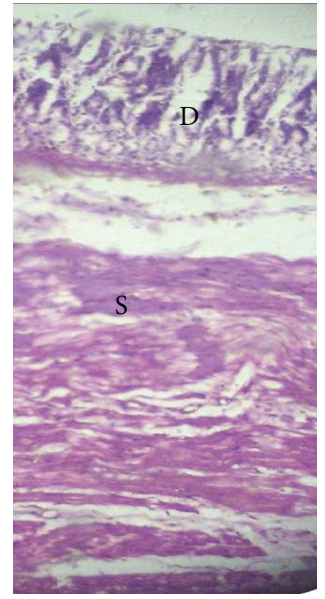

(h)

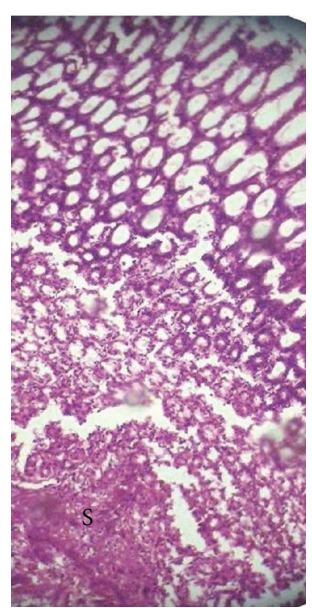

(d)

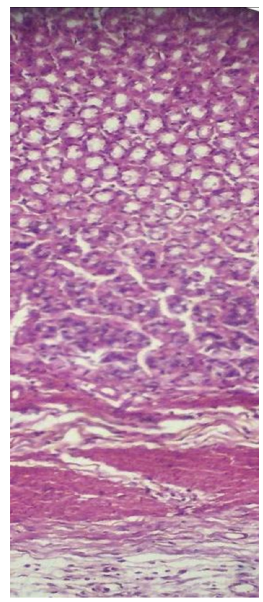

(i)

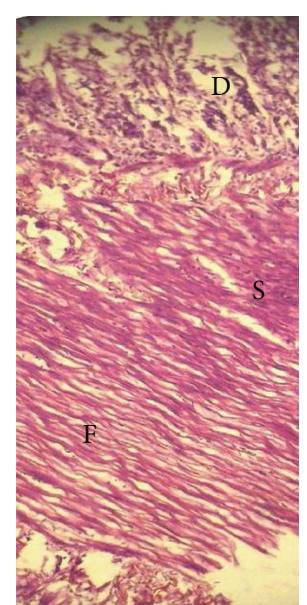

(e)

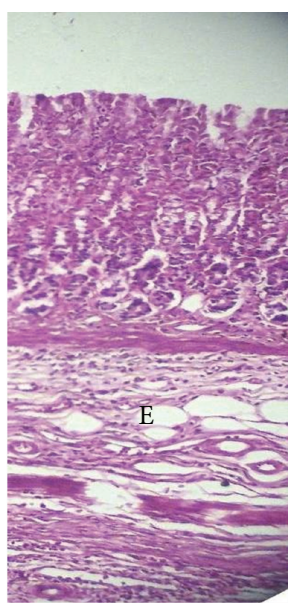

(j)

FIGURE 2: Histological presentation of the chronic acetic acid-induced ulcers: (a): histological section of normal rat stomach showing gastric mucosa (GM), intact annular muscles (AMs), and longitudinal muscles (LMs) in the muscularis. (b)-(f) Histological gastric sections of control rats, day 4 after ulceration and vehicle control (see control 2 and 3, Figure 1) showing the superficial loss of substance, glandular destruction (D), lymphocyte infiltration (I), and sclerosis (S). There was edema (E) and fibrosis (F) in the muscularis mucosa, and blood vessels presented intraparietal leucocyte infiltration, with necrosis and venous congestion. $(\mathrm{g})-(\mathrm{h})$ Stomach sections of rats treated with extract $(125 \mathrm{mg} / \mathrm{kg} \mathrm{bw})$ showing amelioration of gastric tissues, with disappearance of fibrosis but with persistent edema (E) and some glandular destruction (D). (i) Stomach sections of extract-treated rats (250-500 mg/kg bw) after 14-day treatment showing normalization of the mucosa, without glandular destruction and with disappearance of fibrosis, sclerosis, and lymphocyte infiltration. (j): Rats treated with ranitidine showed advanced scar tissue formation, healthy mucosa but with edematous muscularis (E).

SOD is to dismute the superoxide free radicals into hydrogen peroxide. The direct role of oxygen free radicals in the etiopathogenesis of acute stress gastric ulcer has been demonstrated in rats pretreated with allopurinol, a xanthine oxidase inhibitor [37], and cell membrane lipid (polyunsaturated fatty acid) peroxidation is important in the pathogenesis of experimental gastric mucosal injury induced by water immersion stress [38]. In a similar way, oxygen-free radicals are directly implicated in the mechanism of duodenal ulcer relapse and it has been shown that removing the radicals reduces the recurrence of ulceration [39]. The extract of $O$. suave increased the plasma SOD and catalase levels at the dose of $250 \mathrm{mg} / \mathrm{kg}$ compared to the control rats subjected to cold/restraint stress (Table 2), indicating its antioxidant capacity. Catalase intervenes in the degradation of hydrogen peroxide. The dose of $250 \mathrm{mg} / \mathrm{kg}$ of extract reduced levels of malondialdehyde compared with the controls further confirming the in vivo antioxidant power of the extract which was correlated by the in vitro (FRAP) antioxidant capacity.

The polyphenol content of the extract $(899.36 \pm 3.61 \mathrm{mg}$ equivalents of catechin/g of dry extract) is very high like in most species of the genus Ocimum [40]. The antiradical activity of the extract $(89.28 \%)$ measured by the DPPH method was comparable to that of ascorbic acid (93.50\%) and gallic acid (92.05\%) [41]. Given that vitamin C is considered as the most powerful hydrosoluble antioxidant [42], the results suggest that extract of $O$. suave possesses a high antioxidant potential. Qualitative phytochemical tests showed the presence of phenols, flavonoids, sugars, multiple bonds, triterpenes, and sterols but no alkaloids were detected. 
Polyphenolic compounds possess antioxidant activity often attributed to their redox properties which enable them to act like reducing agents and metals chelators, and they scavenge free radicals [43]. Most effective medicinal plants are rich in polyphenols and possess high antioxidant potentials [41]. The preventive antioxidant roles of natural plant substances, for example, flavonoids, polyphenols, carotenoids, vitamins $\mathrm{A}, \mathrm{C}$, and $\mathrm{E}$, and oligoelements like copper and zinc are well known [44]. Flavonoids scavenge free radicals, hinder free radical diffusion, interrupt radical chain reactions, and may have anti-inflammatory activity [45]. Reports [46] have demonstrated the very high antioxidant power of aqueous Ocimum basilicum extract in acute hyperlipidaemia in rats.

Compared to the normal animals not subjected to the stress experience, the stressed untreated control animals showed significant drops in CAT, SOD, and glutathione values. However, in vivo administration of the extract of O. suave before the stress experience resulted in a dose-dependent increase in the CAT, SOD, and glutathione values. On the contrary, MDA dropped at the dose of $250 \mathrm{mg} / \mathrm{kg}$ of extract but increased sharply at the higher dose of $500 \mathrm{mg} / \mathrm{kg}$. The latter results respond to the notion that antioxidants can paradoxically become prooxidant when administered at excessive doses. For this reason, food-derived antioxidants are preferably taken in the form of a composite mixture of many antioxidants with complimentary activity rather than a massive supply of a single antioxidant [23]. The results obtained here may therefore reflect an excessively massive import of a high concentration of the phenol, flavonoid or other potent antioxidant components of the extract at the dose of $500 \mathrm{mg} / \mathrm{kg}$.

In a previous study, the methanol extract of $O$. suave and ranitidine promoted ulcer healing by $81 \%$ and $66 \%$, respectively, after 14 days of treatment [47]. The pain generated by chronic ulcers of the acetic acid type constitutes a source of stress which can lead to increased gastric secretion and the release of reactive oxygen species, and the resulting reduction in blood flow can considerably slow down the healing process. On the other hand, experiments have shown that free radicals are involved in the mechanism of induction of duodenal ulcer pain [48]. The antioxidant capacity of the extract of $O$. suave can therefore speed up the healing process by reducing ischemia and limiting cell damage at the ulcer site. Although acetic acid-induced ulcers present macroscopically as chronic ulcer craters, they are often histologically acute since ulceration does not penetrate beyond the muscularis mucosae. Healing is usually accompanied by fibrosis, mucus secretion, and residual inflammation characteristic of a productive phase of healing that leads to scar formation [49].

During the healing process, mucus production (72$75 \mathrm{mg}$ ) was significantly increased by the extract at the dose of $250-500 \mathrm{mg} / \mathrm{kg}$ compared to the controls and ranitidine (54$58 \mathrm{mg}$ ), offering protection to the ulcer crater against irritant stomach acid secretions and enhancing the local healing process.

\section{Conclusion}

The antioxidant capacity of the extract, the improvement of antioxidant status, and the mucus production enhancing property may be responsible for its ability to promote the healing of chronic gastric ulcers and prevent stressinduced ulcers. The presence of phytochemicals like phenols, flavonoids,and triterpenes may be important but detailed phytochemistry of $O$. suave extract needs to be carried out.

\section{Conflict of Interests}

As the authors of the paper, they do not have a direct financial relation with the commercial identities (Sigma Chemical Co. and Milton Roy Co.) mentioned in their paper that might lead to a conflict of interests.

\section{Acknowledgments}

This project was supported by the International Foundation for Science (FIS), Stockholm, Sweden, and the United Nations University (UNU), Tokyo, Japan, through Grant F/2882-3F awarded to Dr Paul V. Tan. The authors thank Mr. Jean Pierre Takala for preparing histological sections and Dr. Ernestine Nkwengoua for assistance in phytochemical tests.

\section{References}

[1] P. Bugard, "Modern life and gastric stress," Monograph no. 893621/08-90, Imprimerie Le Brun, Caen, France, 1989.

[2] K. Nishida, Y. Ohta, T. Kobayashi, and I. Ishiguro, "Involvement of the xanthine-xanthine oxidase system and neutrophils in the development of acute gastric mucosal lesions in rats with water immersion restraint stress," Digestion, vol. 58, no. 4, pp. 340-351, 1997.

[3] A. S. Salim, "A possible new approach to the problem of refractory peptic ulceration. A role for free radical scavengers?" Scottish Medical Journal, vol. 36, no. 1, pp. 19-20, 1991.

[4] F. Thonner, Flowering Plants of Africa, Weldon and Wesley, New York, NY, USA, 1915, Reprinted 1962 by Cramer and Hafner.

[5] W. C. Burger, "Families of flowering plants in Ethiopia. An Oklahoma State University USAID contract publication," Experimental Bulletin, vol. 45, p. 117, 1967.

[6] J. M. Watt, M. Gerdinat, and K. Breyer-Brandwij, Medicinal and Poisonous Plants of Southern and Eastern Africa, E\&S Livingstone, London, UK, 2nd edition, 1915.

[7] A. Bouquet, "Féticheurs et Médicine Traditionnelles au Congo (Brazzaville)," Memoire O.R.S.T.O.M. no. 36, Paris, France, 1969.

[8] J. Raynal, G. Troupin, and P. Sita, Flore et Médicine Traditionnelles. Mission d'étude 1979 au Rwanda. Rapport présenté a l'Agence de Coopération Culturelle et Technique (ACCT), Paris, France, 1979.

[9] E. N. Mwangi, A. Hassanali, S. Essuman, E. Myandat, L. Moreka, and M. Kimondo, "Repellent and acaricidal properties of Ocimum suave against Rhipicephalus appendiculatus ticks," Experimental and Applied Acarology, vol. 19, no. 1, pp. 11-18, 1995.

[10] A. Seyoum, K. Pålsson, S. Kung’a et al., "Traditional use of mosquito-repellent plants in western Kenya and their evaluation in semi-field experimental huts against Anopheles gambiae: ethnobotanical studies and application by thermal expulsion and direct burning," Transactions of the Royal Society 
of Tropical Medicine and Hygiene, vol. 96, no. 3, pp. 225-231, 2002.

[11] A. Seyoum, G. F. Killeen, E. W. Kabiru, B. G. J. Knols, and A. Hassanali, "Field efficacy of thermally expelled or live potted repellent plants against African malaria vectors in western Kenya," Tropical Medicine and International Health, vol. 8, no. 11, pp. 1005-1011, 2003.

[12] E. Makonnen, A. Debella, D. Abebe, and F. Teka, "Analgesic properties of some Ethiopian medicinal plants in different models of nociception in mice," Phytotherapy Research, vol. 17, no. 9, pp. 1108-1112, 2003.

[13] E. Makonnen, A. Debella, L. Zerihun, D. Abebe, and F. Teka, "Antipyretic properties of the aqueous and ethanol extracts of the leaves of Ocimum suave and Ocimum lamiifolium in mice," Journal of Ethnopharmacology, vol. 88, no. 1, pp. 85-91, 2003.

[14] A. M. Janssen, J. J. C. Scheffer, L. Ntezurubanza, and A. Baerheim Svendsen, "Antimicrobial activities of some Ocimum species grown in Rwanda," Journal of Ethnopharmacology, vol. 26, no. 1, pp. 57-63, 1989.

[15] P. V. Tan, B. Nyasse, T. Dimo, and C. Mezui, "Gastric cytoprotective anti-ulcer effects of the leaf methanol extract of Ocimum suave (Lamiaceae) in rats," Journal of Ethnopharmacology, vol. 82, no. 2-3, pp. 69-74, 2002.

[16] T. A. Miller, "Protective effects of prostaglandins against gastric mucosal damage: current knowledge and proposed mechanisms," The American Journal of Physiology, vol. 245, no. 5, pp. G601-G623, 1983.

[17] J. Bruneton, Phytochemistry and Pharmacognosy of Medicinal Plants: Technics, Lavoisier, 2nd edition, 1993.

[18] Y. Ohta, T. Kobayashi, K. Nishida, M. Nagata, and I. Ishiguro, "Therapeutic effect of Oren-gedoku-to extract on stressinduced acute gastric mucosal lesions in rats," Phytotherapy Research, vol. 13, no. 7, pp. 588-592, 1999.

[19] N. R. Pillai and G. Santhakumari, "Effects of nimbidin on acute and chronic gastro-duodenal ulcer models in experimental animals," Planta Medica, vol. 50, no. 2, pp. 143-146, 1984.

[20] V. L. Singleton, R. Orthofer, and R. M. Lamuela-Raventós, "Analysis of total phenols and other oxidation substrates and antioxidants by means of folin-ciocalteu reagent," Methods in Enzymology, vol. 299, pp. 152-178, 1998.

[21] I. F. F. Benzie and J. J. Strain, "The ferric reducing ability of plasma (FRAP) as a measure of "antioxidant power": the FRAP assay," Analytical Biochemistry, vol. 239, no. 1, pp. 70-76, 1996.

[22] T. Hatano, H. Kagawa, T. Yasuhara, and T. Okuda, "Two new flavonoids and other constituents in licorice root: their relative astringency and radical scavenging effects," Chemical and Pharmaceutical Bulletin, vol. 36, no. 6, pp. 2090-2097, 1988.

[23] K. M. Wilbur, F. Bernheim, and O. W. Shapiro, "Determination of lipid peroxidation," Archives of Biochemistry and Biophysics, vol. 24, pp. 305-310, 1949.

[24] G. L. Ellman, “Tissue sulfhydryl groups”, Archives of Biochemistry and Biophysics, vol. 82, no. 1, pp. 70-77, 1959.

[25] H. P. Misra and I. Fridovich, "The role of superoxide anion in the autoxidation of epinephrine and a simple assay for superoxide dismutase," The Journal of Biological Chemistry, vol. 247, no. 10, pp. 3170-3175, 1972.

[26] A. K. Sinha, "Colorimetric assay of catalase," Annals of Biochemistry, vol. 47, pp. 389-394, 1972.

[27] W. A. Mersereau and E. J. Hinchey, "Effect of gastric acidity on gastric ulceration induced by hemorrhage in the rat, utilizing a gastric chamber technique," Gastroenterology, vol. 64, no. 6, pp. 1130-1135, 1973.
[28] K. G. Lambert and C. H. Kinsley, "Sex differences and gonadal hormones influence susceptibility to the activity-stress paradigm," Physiology and Behavior, vol. 53, no. 6, pp. 10851090, 1993.

[29] K. Somasundaram and A. K. Ganguly, "Gastric mucosal protection during restraint stress in rats: alteration in gastric adherent mucus and dissolved mucus in gastric secretion," HepatoGastroenterology, vol. 32, no. 1, pp. 24-26, 1985.

[30] P. V. Tan, C. Mezui, and M. Boda, "Anti-Helicobacter and gastroduodenal cytoprotective actions of the leaf aqueous extract of Ocimum suave (Lamiaceae)," Journal of Medicinal Plants Research, vol. 5, no. 25, pp. 5958-5966, 2011.

[31] T. Coskun, I. Alican, B. C. Yegen, T. San, S. Cetinel, and H. Kurtel, "Cyclosporin A reduces the severity of cold-restraintinduced gastric lesions: role of leukocytes," Digestion, vol. 56, no. 3, pp. 214-219, 1995.

[32] A. S. Salim, "Removing oxygen-derived free radicals stimulates healing of ethanol-induced erosive gastritis in the rat," Digestion, vol. 47, no. 1, pp. 24-28, 1990.

[33] M. Itoh and P. H. Guth, "Superoxide radicals play a role in haemorrhagic shock-induced gastric lesions in the rat," Gastroenterology, vol. 82, p. 1122, 1984.

[34] A. S. Salim, "Role of oxygen-derived free radicals in mechanism of acute and chronic duodenal ulceration in the rat," Digestive Diseases and Sciences, vol. 35, no. 1, pp. 73-79, 1990.

[35] M. Kolomoets, I. V. Kuz'menko, L. A. Chernukhina, and E. P. Klimenko, "Role of alpha tocopherol and retinol in the antiradical protection of the body in peptic ulcer," Ukraïns'khyï Biokhimichnyï Zhurnal (Kiev), vol. 64, no. 2, pp. 79-84, 1992.

[36] T. Ohara, S. Asaki, and T. Toyota, "Biological evaluation of extracellular superoxide dismutase observed in a state of acute gastric mucosal lesions," Japanese Journal of Gastroenterology, vol. 87, no. 1, pp. 1-7, 1990.

[37] S. Mancinelli, G. de la Fuente, V. Manríquez et al., “The etiopathogenesis of the acute stress ulcer. The role of oxygen free radicals," Revista Medica de Chile, vol. 118, no. 9, pp. 965-970, 1990.

[38] R. Tandon, H. D. Khanna, M. Dorababu, and R. K. Goel, "Oxidative stress and antioxidants status in peptic ulcer and gastric carcinoma," Indian Journal of Physiology and Pharmacology, vol. 48, no. 1, pp. 115-118, 2004.

[39] A. S. Salim, "Oxygen-derived free radicals and the prevention of duodenal ulcer relapse: a new approach," American Journal of the Medical Sciences, vol. 300, no. 1, pp. 1-8, 1990.

[40] J. Javanmardi, C. Stushnoff, E. Locke, and J. M. Vivanco, "Antioxidant activity and total phenolic content of Iranian Ocimum accessions," Food Chemistry, vol. 83, no. 4, pp. 547550, 2003.

[41] A. C. Akinmoladun, E. O. Ibukun, E. Afor et al., "Chemical constituents and antioxidant activity of Alstonia boonei," African Journal of Biotechnology, vol. 6, no. 10, pp. 1197-1201, 2007.

[42] I. Klimczak, M. Malecka, M. Szlachta, and A. GliszczynskaSwiglo, "Effect of storage on the contenent of polyphénols, vitamin $\mathrm{C}$ and the antioxidant activity of orange juices," $\mathrm{Al}$ Niepodl, vol. 10, pp. 960-967, 2006.

[43] C. A. Rice-Evans, N. J. Miller, and G. Paganga, "Structureantioxidant activity relationships of flavonoids and phenolic acids," Free Radical Biology and Medicine, vol. 20, no. 7, pp. 933956, 1996. 
[44] A. Favier, "Le stress oxydant: Intérêt conceptuel et expérimental dans la compréhension des mécanismes des maladies et potentiel thérapeutique," L’ Actualité Chimique, no. 11-12, pp. 108-115, 2003.

[45] M. G. L. Hertog, E. J. M. Feskens, P. C. H. Hollman, M. B. Katan, and D. Kromhout, "Dietary antioxidant flavonoids and risk of coronary heart disease: The Zutphen Elderly Study," The Lancet, vol. 342, no. 8878, pp. 1007-1011, 1993.

[46] S. Amrani, H. Harnafi, N. E. H. Bouanani et al., "Hypolipidaemic activity of aqueous Ocimum basilicum extract in acute hyperlipidaemia induced by triton WR-1339 in rats and its antioxidant property," Phytotherapy Research, vol. 20, no. 12, pp. 1040-1045, 2006.

[47] P. V. Tan, C. Mezui, G. Enow-Orock, T. Dimo, and B. Nyasse, "Healing effect on chronic gastric ulcers and shortterm toxicity profile of the leaf methanol extract of Ocimum suave(Lamiaceae) in rats," African Journal of Traditional, Complimentary and Alternative Medicine, vol. 2, no. 3, pp. 312-325, 2005.

[48] O. Pascu and D. Dejica, "Oxygen free radicals and duodenal ulcer pain. Preliminary data," Medecine Interne, vol. 25, no. 2, pp. 81-84, 1987.

[49] P. V. Tan, B. Nyasse, G. E. Enow-Orock, P. Wafo, and E. A. Forcha, "Prophylactic and healing properties of a new anti-ulcer compound from Enantia chlorantha in rats," Phytomedicine, vol. 7, no. 4, pp. 291-296, 2000. 


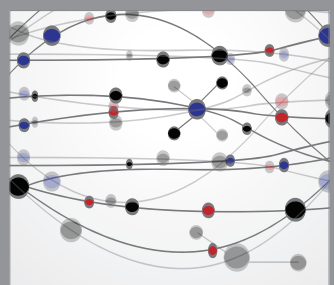

The Scientific World Journal
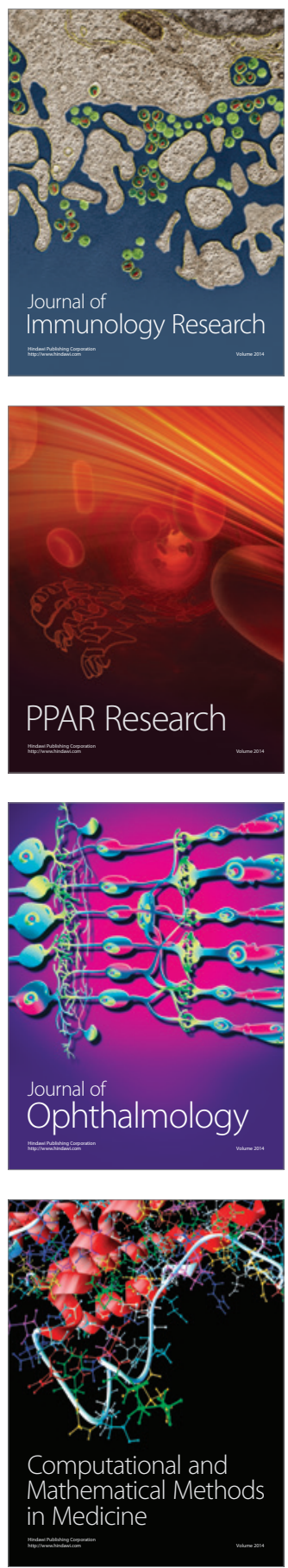

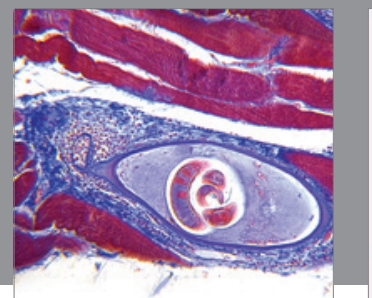

Gastroenterology

Research and Practice
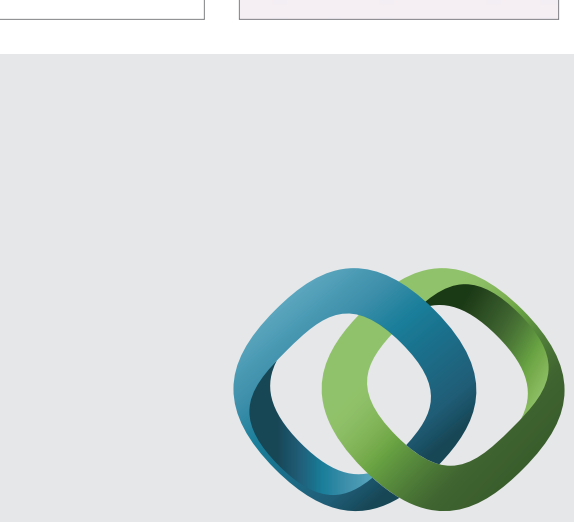

\section{Hindawi}

Submit your manuscripts at

http://www.hindawi.com
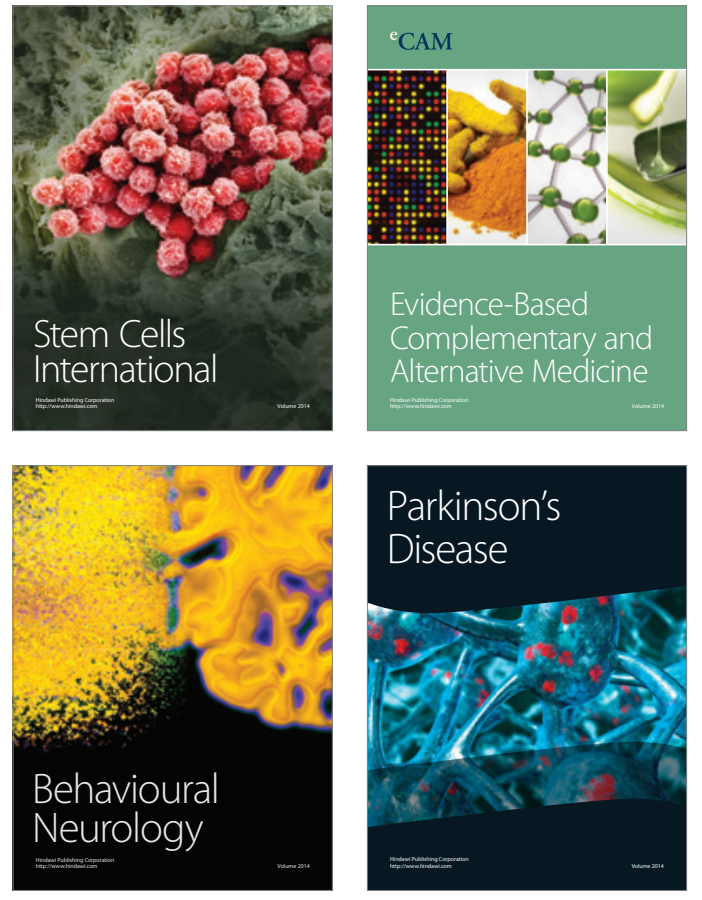
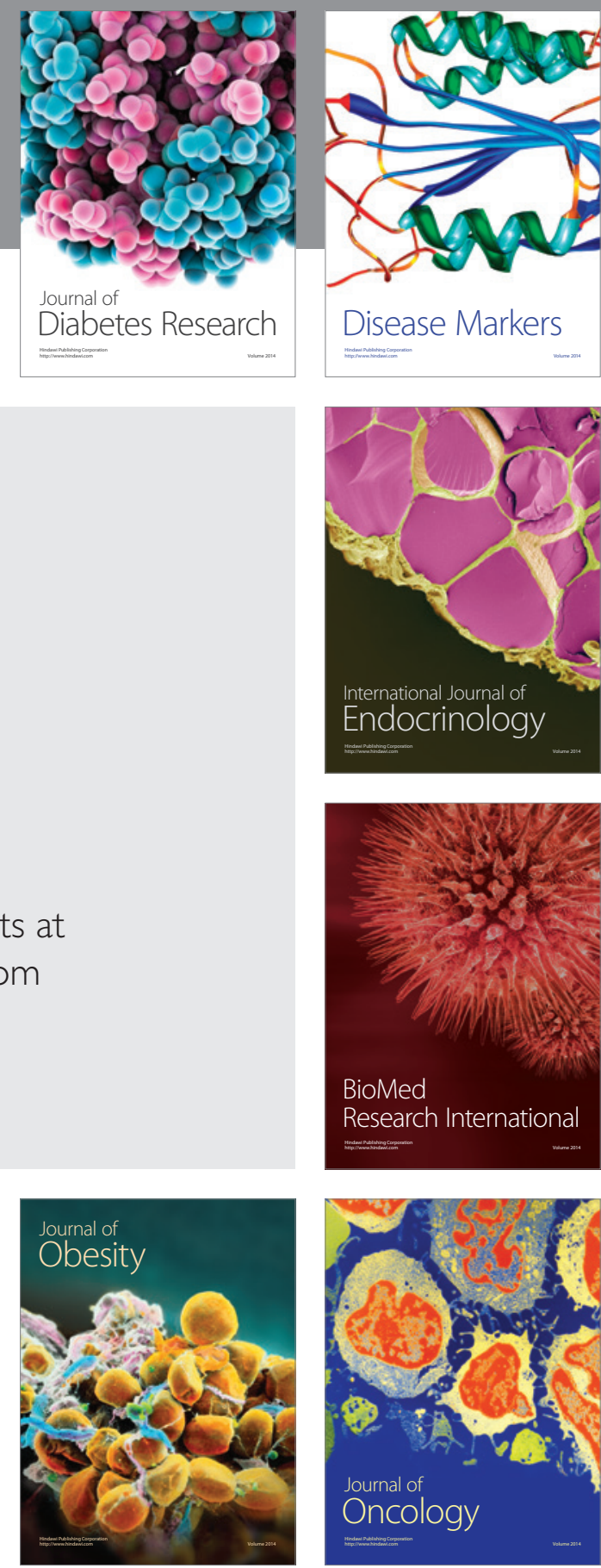

Disease Markers
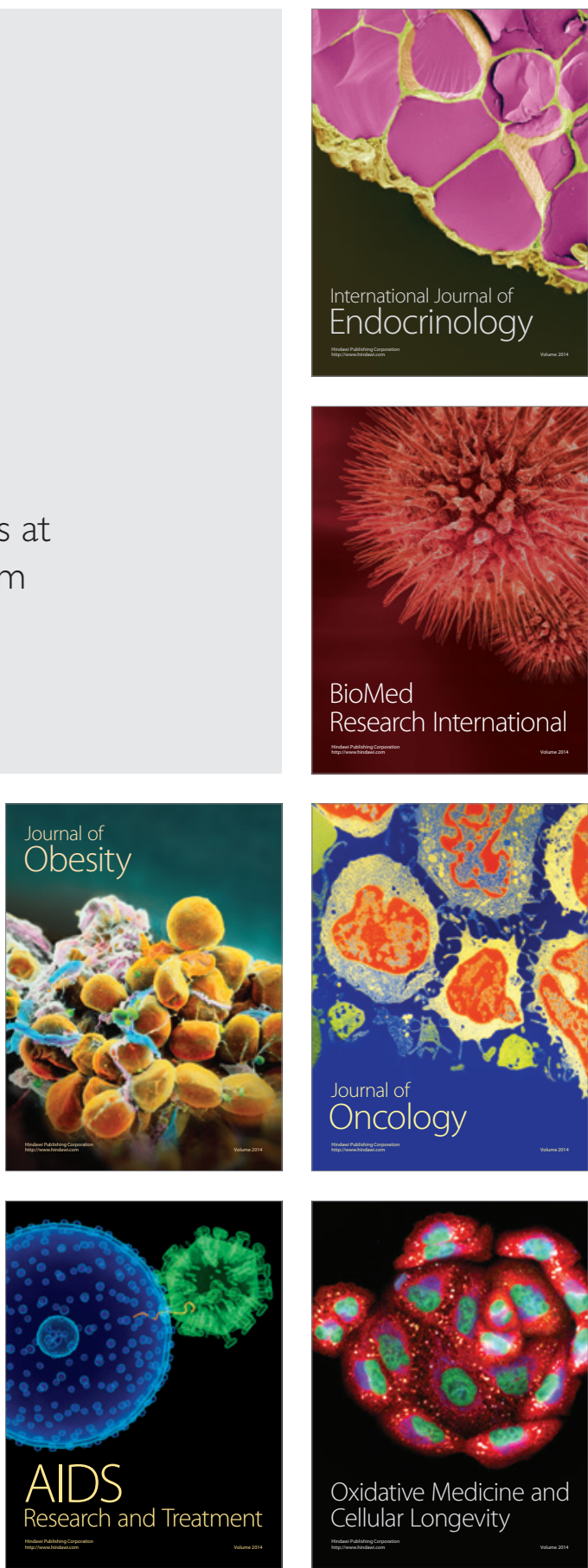